\title{
Identifikasi Telajakan di Desa Pakraman Nyuh Kuning, Kecamatan Ubud Kabupaten Gianyar
}

\section{KETUT GDE MAYUN MAHARDIKA ${ }^{1 *}$, A.A. GEDE DALEM SUDARSANA ${ }^{1}$, A.A. GEDE SUGIANTHARA ${ }^{1}$}

1. Program Studi Agroekoteknologi, Fakultas Pertanian, Universitas Udayana, Jln. PB. Sudirman, Denpasar 80362 Bali

*E-mail: mayungeriya@gmail.com

\section{ABSTRACT \\ Telajakan Identification in Desa Pakraman Nyuh Kuning, Kecamatan Ubud Kabupaten Gianyar}

The customary village or desa pakraman of Nyuh Kuning located in the administrative village of Mas Village, Ubud District, Gianyar Regency, and is bounded by several natural and cultural tourism places. The village which is located in tourism centers usually threatened by traditional degradation such as the lost of telajakan or front yard garden. In contrary, telajakan still preserved in desa pakraman Nyuh Kuning. The aims of the study were to investigate the function and development of telajakan in Nyuh Kuning and the commitment villagers in managing telajakan. Some methods were used such as questionnaire surveys, interviews, observations and literature study. The results showed that $75 \%$ of respondents knew the function and consider to the development of telajakan and it develop into different sizes, forms, and functions. The structure of telajakan were dominated by flowers i.e. frangipani (88\%); gardenia (3\%); bougainvillia (2\%); roses (2\%); and hibiscus (5\%). The respondents motivation to preserved and manage telajakan in order to keep Nyuh Kuning become tourism destination.

Keywords: telajakan, desa pakraman Nyuh Kuning, Ubud

\section{Pendahuluan}

Aktivitas budaya yang dilaksanakan oleh masyarakat Bali terpusat pada desa pakraman dengan konsep dasar Tri Hita Karana yaitu tiga hubungan harmonis antara manusia dengan Tuhan, manusia dengan manusia, dan manusia dengan lingkungan yang dijabarkan dengan adanya parahyangan, pawongan, dan palemahan. Desa pakraman terdiri dari tiga unsur, di antaranya unsur parahyangan yaitu pura atau tempat suci agama Hindu, unsur pawongan yaitu warga desa pakraman setempat, unsur palemahan yaitu wilayah desa yang berupa Karang Ayah Desa dan Karang Guna Kaya (Windia, 2010).

Konsep Tri Hita Karana akan menurunkan kosep Tri Mandala dalam pola pembagian tata ruang yaitu utama mandala, madya mandala dan nista mandala. Pertamanan Tradisional Bali menggunakan konsep Tri Mandala, dengan pembagian ruang dibedakan berdasarkan fungsi dari masing-masing ruang tersebut. Pembagian ruang 
berkaitan pula dengan jenis tanaman yang ditanami sesuai dengan filosofi, fungsi dan nilainya (Dwijendra, 2010).

Tanaman adalah salah satu elemen pendukung keindahan taman dan sebagai pengisi area kosong pekarangan. Estetika atau keindahan dipengaruhi oleh faktor fisik tanaman sesuai dengan fungsi penanaman seperti untuk pagar, naungan, proteksi, pengarah jalan dan sebagainya (Sardiana dkk., 2012).

Desa Pakraman Nyuh Kuning terletak di Desa Dinas Mas Kecamatan Ubud dan berbatasan langsung dengan beberapa desa yang terkenal dengan pariwisata alam dan budayanya, seperti Desa Peliatan, Kelurahan Ubud, Desa Pakraman Lodtunduh, dan Desa Pakraman Pengosekan. Desa-desa yang berada di pusat pariwisata tersebut mulai kehilangan komponen-komponen penyusun rumah tradisional, seperti telajakan. Desadesa yang berbatasan dengan Desa Pakraman Nyuh Kuning mengalami alih fungsi lahan telajakan yang umumnya digunakan sebagai prasarana pendukung kegiatan ekonomi.

Lestarinya telajakan di Desa Pakraman Nyuh Kuning ternyata menjadi daya tarik tersendiri bagi pariwisata. Identifikasi telajakan di desa ini perlu dilakukan untuk mempelajari fungsi, perkembangan dan mekanisme pengelolaannya, sehingga salah satu warisan tata ruang tradisional Bali tetap lestari.

\subsection{Rumusan Masalah}

1. Apa fungsi telajakan Desa Pakraman Nyuh Kuning?

2. Bagaimana perkembangan telajakan Desa Pakraman Nyuh Kuning?

3. Bagaimana antusiasme masyarakat Desa Pakraman Nyuh Kuning dalam pengelolaan telajakan?

\subsection{Tujuan Penelitian}

1. Mengetahui fungsi dari telajakan yang terdapat di Desa Pakraman Nyuh Kuning.

2. Mengetahui perkembangan telajakan Desa Pakraman Nyuh Kuning hingga sekarang.

3. Mengetahui seberapa jauh antusiasme masyarakat Desa Pakraman Nyuh Kuning dalam pengelolaan telajakan.

\subsection{Manfaat Penelitian}

a. Bagi Pemerintah yaitu sebagai bahan acuan dan pertimbangan untuk mengambil suatu kebijakan di dalam penataan telajakan.

b. Bagi masyarakat luas yaitu sebagai acuan untuk menata dan melestarikan telajakan.

c. Bagi profesi Arsitektur Lansekap yaitu memahami fungsi dan perkembangan serta pengelolaan telajakan di Desa Pakraman Nyuh Kuning.

d. Manfaat penelitian secara teoritis merupakan sumbangan bagi ilmu pengetahuan khususnya dalam bidang Arsitektur Lansekap yang membahas dan mendalami tentang telajakan baik di lihat dari fungsi dan perkembangannya.

\subsection{Ruang Lingkup Penelitian}

Penelitian ini dilakukan di Desa Pakraman Nyuh Kuning, Desa Mas, Kecamatan Ubud, Kabupaten Gianyar dengan objek penelitian telajakan. Ruang lingkup penelitian ini adalah melakukan identifikasi dalam fungsi telajakan terhadap tata ruang tradisional Bali, 
mempelajari perkembangannya seperti ukuran lebar, jenis tanaman pada jaman dahulu dan sekarang, serta mengamati antusiasme warga desa untuk mengelola telajakan.

\section{Metode}

\subsection{Tempat dan Waktu Penelitian}

Penelitian ini bertempat di Desa Pakraman Nyuh Kuning, Desa Mas Kecamatan Ubud, Kabupaten Gianyar. Penelitian ini dilaksanakan pada bulan Juni 2014 sampai Januari 2015 (Gambar 1).

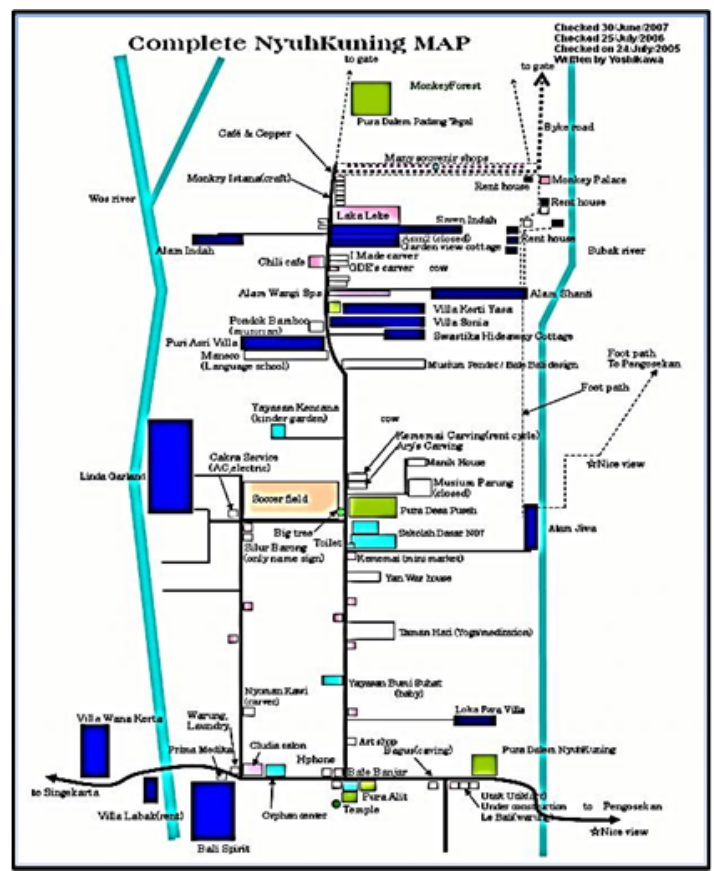

Sumber: http//:forum.realityfanforum.com

Gambar 1. Peta Lokasi Desa Pakraman Nuh Kuning Ubud

\subsection{Bahan dan Alat}

Bahan dan alat yang digunakan antara lain adalah kuesioner, kamera digital, alat ukur (meteran), sound recorder dan perangkat komputer untuk mengolah data.

\subsection{Metode Penelitian}

Penelitian ini menggunakan metode survey dengan teknik pengumpulan data dengan cara wawancara, penyebaran kuesioner, observasi lapangan dan studi kepustakaan.

Jenis data yang digunakan dalam penelitian ini adalah data primer dan data sekunder. Data primer berupa hasil observasi di lapangan, sedangkan data sekunder diperoleh berdasarkan studi kepustakaan yang meliputi jurnal, buku, data desa dan media internet.

Teknik pengumpulan data yang digunakan dalam penelitian ini antara lain: 


\section{a) Wawancara}

Pengumpulan data dengan bertanya kepada beberapa narasumber secara langsung. Narasumber adalah Made Weda (Kelihan Adat) dan dua tokoh masyarakat diantaranya: I Ketut Muka Pendet dan I Wayan Sugiartha. Pertanyaan yang diajukan kepada responden terkait dengan fungsi telajakan, perkembangan serta antusiasme dalam melestarikan telajakan.

b) Kuesioner

Pengumpulan data dilakukan dengan menggunakan kuisioner yang di sebarkan kepada 40 orang responden sebagai sampel yaitu 50\% dari pemilik telajakan. Data yang diambil terkait dengan fungsi dari telajakan, perkembangan serta antusiasme dari masyarakat dalam pengelolaan telajakan di Desa Pakraman Nyuh Kuning.

c) Observasi

Pengumpulan data yang dilakukan ke setiap telajakan. Data yang diamati terkait dengan fungsi telajakan, jenis tanaman dan perkembangan yang terjadi di lapangan.

d) Studi Kepustakaan

Merupakan pengumpulan data penelitian melalui studi kepustakaan baik yang ada di desa pakraman Nyuh Kuning, pada dinas atau instansi terkait, buku-buku, referensi maupun media internet.

Cara pengambilan sampel untuk memperoleh data penelitian menggunakan teknik purposive sampling. Menurut Amirin (2012) purposive sampling adalah pengambilan sampel secara sengaja sesuai dengan persyaratan sampel yang diperlukan. Jumlah sampel dalam penelitian ini ditetapkan sebanyak 40 rumah (50\% dari total jumlah rumah pemilik telajakan) yang dianggap dapat mewakili seluruh pemilik telajakan. Tempat kedudukan pengambilan titik sampel tertera pada Gambar 2. Penelitian ini dilakukan secara spesifik yang dilaksanakan di Desa Pakraman Nyuh Kuning.

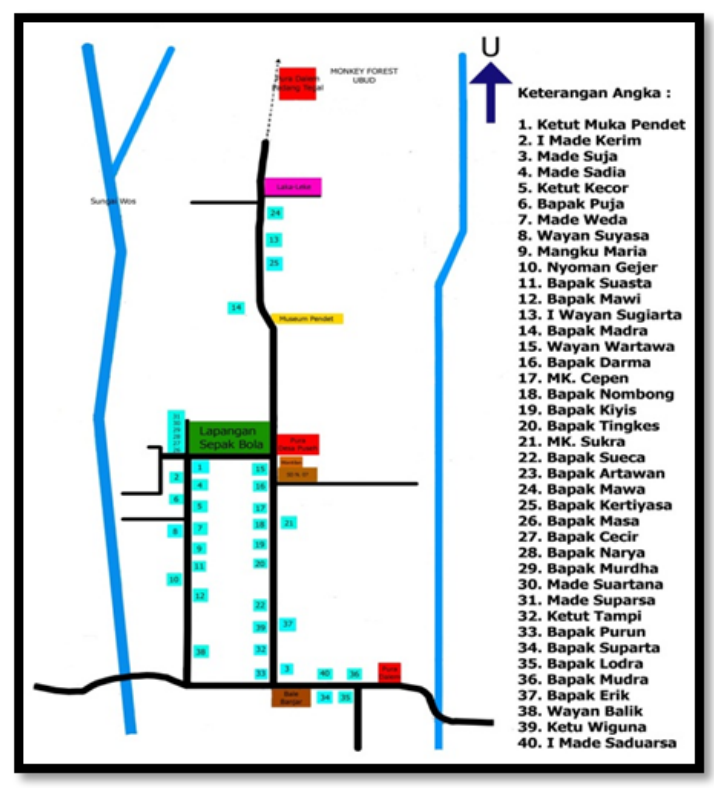

Gambar 2. Peta Pengambilan Sampel Penelitian di Desa Pakraman Nyuh Kuning. 


\subsection{Analisis Data}

Data yang telah diperoleh selanjutnya dilakukan analisis secara deskriptif kualitatif sehingga didapatkan kesimpulan sesuai dengan fakta dan permasalahan di lapangan. Data yang bersifat kuantitatif akan ditampilkan dalam bentuk tabel yang telah diolah dengan rumus :

$$
P=\frac{f}{N} \times 100 \%
$$

Keterangan :

$P=$ Presentase

$\mathrm{f}=$ Frekuensi

$N=\sum$ Total Responden

\section{Hasil dan Pembahasan}

\subsection{Fungsi Telajakan}

Secara fisik, ada tiga fungsi utama dari telajakan yaitu sebagai penghijauan, menjaga lingkungan dan mempertahankan sempadan bangunan demi keamanan dan kenyamanan bangunan serta lingkungannya (Dwijendra, 2010).

Hasil penelitian menyatakan sebanyak $75 \%$ warga mengetahui fungsi telajakan dan 25\% warga kurang mengetahuinya. Desa Pakraman Nyuh Kuning memiliki telajakan yang sering disebut ambal-ambal. Warga Desa Pakraman Nyuh Kuning menggunakan telajakan sebagai :

a. Tempat menanam tanaman (Landscape) yaitu telajakan di fungsikan sebagai penghijauan.

b. Sebagai ruang atau jarak antara tembok rumah dengan jalan raya (Space) yaitu pentingnya jarak demi keamanan dan kenyamanan yang tercapai.

c. Tempat patung (Sclupture) yaitu meletakkan patung di antara angkul-angkul pemilik rumah dengan model patung yang beragam sesuai dengan selera pemilik rumah.

d. Tempat menancapkan penjor pada saat hari raya Galungan dan Kuningan dan atau pada saat karya agung.

e. Elemen penunjang lainnya seperti kegiatan sosial yaitu tempat menaruh ayam kurungan, memberi pinjaman area telajakan kepada tetangga yang kekurangan tempat untuk menjemur hasil pertanian, memperkokoh tembok penyengker, dan menambah keindahan bagian depan pekarangan.

\subsection{Perkembangan Telajakan Desa Pakraman Nyuh Kuning}

Berdasarkan penelitian yang telah dilakukan, hasil menunjukan bahwa 90\% warga mengatakan tidak ada perubahan lebar telajakan dan 10\% mengatakan terjadi perubahan tersebut (dari lebar $100 \mathrm{~cm}$ menjadi $75 \mathrm{~cm}$ ) karena terbatasnya ruang untuk membuat tembok pembatas rumah sehingga mengorbankan sedikit area telajakan.

Perubahan lebar telajakan menjadi minimal $75 \mathrm{~cm}$ dimaklumi karena adanya awigawig yang secara tradisional menentukan lebar telajakan sekurang-kurangnya $75 \mathrm{~cm}$. Jika lebar telajakan kurang dari $75 \mathrm{~cm}$, pelanggaran terhadap awig-awig tersebut memiliki 
konsekuensi berupa pembongkaran bangunan di area telajakan dan kemudian dikembalikan menjadi telajakan oleh yang bersangkutan yang tertulis dalam awig-awig Desa Pakraman Nyuh Kuning, 1994.

Berbeda halnya dengan jenis tanaman yang ditanam sudah mengalami perkembangan dan perubahan bila dibandingkan dengan satu dekade sebelumnya. Perubahan tersebut disajikan pada Tabel 1 dan Tabel 2.

Tabel 1. Jenis Tanaman yang Ditanam di Telajakan Desa Pakraman Nyuh Kuning pada Periode Tahun 1990 an.

\begin{tabular}{cccc}
\hline No & Nama Latin & Nama Lokal & Presentase (\%) \\
\hline 1 & Musa paradisiaca & Pisang & 20 \\
2 & Cocos nucifera & Kelapa & 40 \\
3 & Carica papaya & Pepaya & 10 \\
4 & Plumeria sp. & Kamboja & 20 \\
5 & Bougainvillea spectabilis & Kembang Kertas & 5 \\
6 & Rosa sp. & Mawar & 5 \\
\hline
\end{tabular}

Sumber: Hasil Kuesioner Responden

Tabel 1 menunjukkan bahwa pada periode tahun 1990, tanaman kelapa (Cocos nucifera) merupakan tanaman favorit yang ditanam di telajakan yaitu sebanyak 40\%, berbeda halnya dengan pisang (Musa paradisiaca) 20\%, pepaya (Carica papaya) $10 \%$, Kamboja (Plumeria sp.) 20\%, kembang kertas (Bougainvillea spectabilis) 5\% dan mawar (Rossa sp.) 5\%. Pada saat itu diketahui bahwa Desa Pakraman Nyuh Kuning identik dengan pohon kelapanya. Kelapa-kelapa tersebut tidak hanya ditanam di ladang melainkan juga sebagai komponen utama penyusun telajakan.

Tabel 2. Jenis Tanaman pada Telajakan Desa Pakraman Nyuh Kuning pada Tahun 2015

\begin{tabular}{cccccc}
\hline No & $\begin{array}{c}\text { Jenis } \\
\text { Tanaman }\end{array}$ & Nama Lokal & Nama Latin & Jumlah & $\%$ \\
\hline \multirow{2}{*}{1} & \multirow{3}{*}{ Rumput } & Rumput Jepang & Zoysia japonica & $25 \mathrm{~m}^{2}$ & 17 \\
& & Rumput Mutiara & Hedyotis corymbosa & $40 \mathrm{~m}^{2}$ & 28 \\
& & Rumput Gajah Mini & Pennisetum purpureum & $80 \mathrm{~m}^{2}$ & 55 \\
& Sub Total & & & $145 \mathrm{~m}^{2}$ & 100 \\
& & Kamboja & Plumeria sp. & $259 \mathrm{phn}$ & 88 \\
& & Jempiring & Gardenia jasminoides & $10 \mathrm{phn}$ & 3 \\
2 & \multirow{2}{*}{ Bunga } & Kembang kertas & Bougenville sp. & $5 \mathrm{phn}$ & 2 \\
& & Mawar & Rosa sp. & $6 \mathrm{phn}$ & 2 \\
& & Kembang sepatu & Hibiscus rosa-sinensis & $14 \mathrm{phn}$ & 5 \\
& \multirow{4}{*}{ Sub Total } & & & $294 \mathrm{phn}$ & 100 \\
& & Mangga & Mangifera indica & $3 \mathrm{phn}$ & 42 \\
3 & Buah & Rambutan & Nephellium lappacium & $2 \mathrm{phn}$ & 29 \\
& & Kelapa & Cocos nucifera & $2 \mathrm{phn}$ & 29 \\
& & & & $7 \mathrm{phn}$ & 100 \\
\hline
\end{tabular}

Sumber: Hasil Observasi Lapangan, 2015

Saat ini tanaman-tanaman penyusun telajakan cukup beragam yang didominasi oleh tanaman bunga kamboja (Plumeria sp.) dan beberapa tanaman bunga lainnya yaitu: 
jempiring (Gardenia jasminoides), kembang kertas (Bougenville), mawar (Rosa) dan kembang sepatu (Hibicus rosa-sinensis). Selain target 5000 pohon kamboja, penanaman pohon kamboja disebabkan oleh tingginya keperluan warga terhadap bunga kamboja untuk sarana kegiatan keagamaan seperti untuk sarana banten dan sembahyang. Weda (prescom, 2015). Beralihnya warga dari menanam kelapa menjadi menanam kamboja di telajakan disebabkan oleh adanya kebijakan yang telah disepakati oleh Desa Pakraman karena buah kelapa yang jatuh ke jalan raya dinilai membahayakan, maka dari itu maskot Desa Pakraman Nyuh Kuning digantikan menjadi bunga kamboja. Tidak hanya bungabungaan, komponen lain penyusun telajakan saat ini adalah rumput-rumputan dan buahbuahan. Rumput yang umum di pakai adalah rumput gajah mini (Pennisetum purpureum), rumput mutiara (Hedyotis corymbosa) dan rumput jepang (Zoysia japonica). Tanaman buah-buahan yang masih ada seperti rambutan (Nephellium lappacium), mangga (Mangifera indica) dan kelapa (Cocos nucifera).

Perkembangan fungsi telajakan Desa Pakraman Nyuh Kuning ditunjukkan oleh 80\% responden yang mengatakan terjadi perkembangan tersebut baik dari segi bentuk, lebar dan jenis tanaman yang di tanami, sisanya mengatakan tidak. Perkembangan telajakan di mulai dari tahun 1990 yang di bersihkan dan di tata oleh Desa Pakraman Nyuh Kuning. Pada periode 1990 sampai 1995 telajakan mulai di fungsikan sesuai dengan kegiatan yang ada di desa seperti dijadikan tempat menaruh ayam kurungan, tempat menanam tanaman, tempat duduk santai. Sugiartha (prescom, 2014). Telajakan berbentuk alami sesuai dengan situasi dan keadaan di tapak sesuai dengan bentuk aslinya. Telajakan di tanam berbagai jenis tanaman di antaranya pisang (Musa paradisiaca), kelapa (Cocos nucifera), mangga (Mangifera indica) dan beberapa tanaman hias seperti kamboja (Plumeria sp.) kembang kertas (Bougainvillea spectabilis), mawar (Rosa sp.) dan lain-lain.

Tahun 1996 - 2000 telajakan mulai di kelola dan di lestarikan oleh seluruh masyarakat Desa Pakraman Nyuh Kuning, dibuktikan dengan pengesahan awig-awig tentang telajakan pada tahun 1994. Telajakan mulai di tata sedemikian rupa dan didukung dengan adanya inovasi dan variasi yang terjadi di setiap telajakan sesuai dengan selera pemiliknya. Model telajakan yang ada di Nyuh Kuning dari datar sampai berterastering sesuai keadaan tapak.
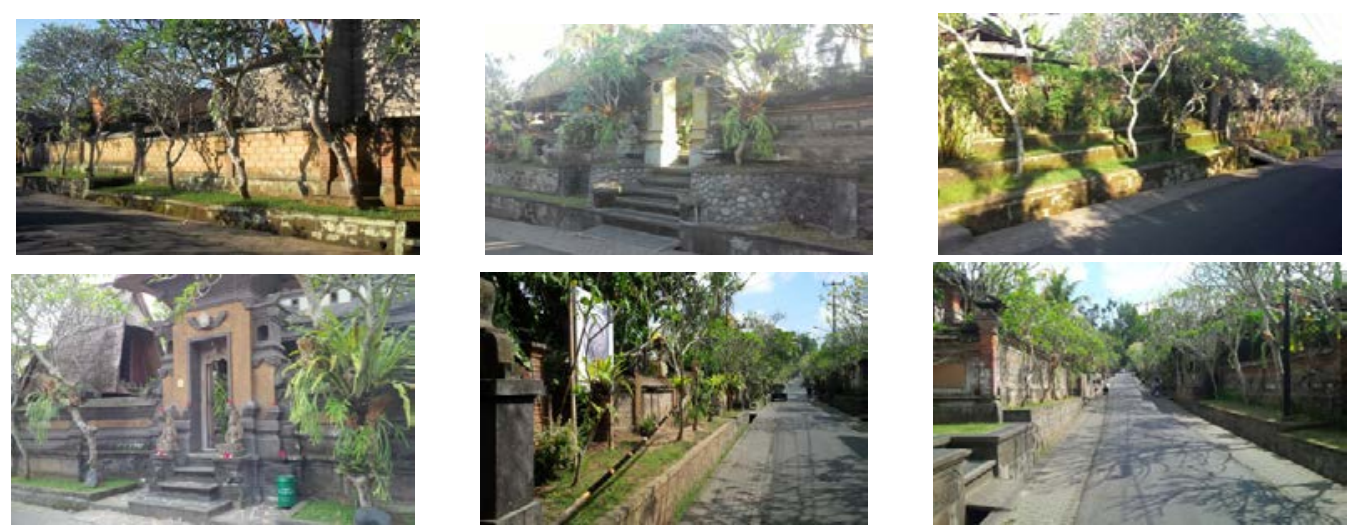

Gambar 3. Telajakan Desa Pakraman Nyuh Kuning Ubud (2014). 
Pada tahun 2000-2015 (sampai sekarang), dari hasil pengamatan yang telah dilakukan telajakan dalam keadaan baik dan lestari. Saat ini yang dilakukan adalah perawatan dan pengelolaannya untuk tetap dapat menjaga dan melestarikan telajakan tersebut. Perawatan telajakan di laksanakan setiap hari minggu pada pagi hari oleh seluruh warga. Taman telajakan di kelola oleh Desa Pakraman Nyuh Kuning dan dibantu oleh tim lingkungan yang telah di bentuk. Telajakan masih tetap dilestarikan dan asri karena kesadaran dari masyarakat dan kesepakatan bersama untuk tetap mempertahankan serta menjaga keasrian telajakan. Muka (prescom, 2015).

\subsection{Antusiasme dan Pelestarian Warga Desa Pakraman Nyuh Kuning Terhadap Telajakan.}

Telajakan Desa Pakraman Nyuh Kuning sepenuhnya diatur oleh desa melalui awigawig desa yang diterbitkan pada tahun 1994. Pengelolaan telajakan yang dilakukan oleh seluruh masyarakat Nyuh Kuning sangat baik karena sesuai dengan awig-awig dan di atur oleh desa.

Warga Desa Pakraman Nyuh Kuning memiliki tim khusus yang bergerak menangani telajakan. Telajakan di tata sedemikian rupa agar tetap lestari, indah dan bersih. Selain adanya tim lingkungan, seluruh masyarakat ikut berpartisipasi dan memiliki tekad yang tinggi dalam pengelolaannya. Masyarakat mengetahui pentingnya telajakan tersebut di lihat dari fungsi dan manfaatnya baik dalam bidang ekonomi, sosial, agama dan sektor pariwisata. Muka (prescom 2015).

Dari hasil penelitian yang dilakukan, diketahui bahwa seluruh warga menyatakan adanya pengaruh positif dari telajakan terhadap kehidupan bermasyarakat. Telajakan berpengaruh positif terhadap kehidupan warga Desa Pakraman Nyuh Kuning yaitu selain memberikan suasana yang sejuk dan hijau, juga meningkatnya taraf hidup masyarakat yang bersumber dari sektor pariwisata. Seluruh masyarakat Nyuh Kuning melestarikan telajakan dengan tujuan menarik daya tarik wisatawan untuk berkunjung ke desanya. Dengan cara tersebut masyarakat memperoleh keuntungan di bidang ekonomi dan pariwisata.

Sumber dana yang digunakan dalam pengelolaan telajakan dan pedestrian (paving) berasal dari swadaya dan sumbangan dari wisatawan yang berkunjung ke Nyuh Kuning. Jarak Nyuh Kuning berdekatan dengan Monkey Forest Ubud yang merupakan kawasan destinasi pariwisata berupa hutan lindung, sehingga mendapat imbasan secara tidak langsung kunjungan dari wisatawan baik domestik maupun manca negara. Para wisatawan melihat secara langsung keasrian telajakan yang merupakan warisan leluhur tradisional Bali di dalam taman tradisional Bali.

Jalan masuk ke desa terdapat pos penjaga untuk memungut sumbangan terhadap wisatawan yang masuk ke desa. Wisatawan dikenakan biaya seikhlasnya dengan maksud dan tujuan untuk dapat membantu pengelolaan dan pelestarian dari telajakan yang berada di lingkungan Desa Pakraman Nyuh Kuning. Dana tersebut dikelola oleh desa untuk menunjang aktivitas tim lingkungan dan pemeliharaan sarana jalan. Sugiartha (prescom, 2015). 
Semangat masyrakat Desa Pakraman Nyuh Kuning dalam pengelolaan dan pelestarian lingkungan yang salah satunya berupa telajakan membuahkan hasil dan mendapatkan kepuasan tersendiri. Tahun 2010 hingga 2013, Desa Pakraman Nyuh Kuning selalu menjadi juara dalam event lingkungan hidup tingkat daerah maupun nasional. Beberapa prestasi yang pernah di raih adalah sebagai berikut:

1. Juara I Desa Sadar Lingkungan Tingkat Provinsi Tahun 2010.

2. Juara I Prilaku Bersih dan Sehat Tingkat Provinsi 2011.

3. Juara III Kebersihan Lingkungan Tingkat Nasional 2012.

4. Juara I Permukiman Tingkat Nasional 2013.

Prestasi ini di capai karena semangat dan antusias yang dimiliki masyarakat Nyuh Kuning sangat tinggi. Masyarakat desa mentaati dan melaksanakan peraturan yang telah di buat serta disepakati bersama-sama sehingga tujuan yang di inginkan telah tercapai. Muka (prescom, 2015).

\section{Simpulan}

\subsection{Simpulan}

Hasil penelitian ini menyimpulkan beberapa hal sebagai berikut:

1. Seluruh rumah warga Desa Pakraman Nyuh Kuning memiliki telajakan.

2. Telajakan Desa Pakraman Nyuh Kuning berfungsi sebagai: tempat menanam tanaman, sebagai ruang terbuka hijau, tempat patung, tempat menancapkan penjor dan elemen penunjang lainnya seperti kegiatan sosial yaitu tempat menaruh ayam kurungan, memberi pinjaman area telajakan kepada tetangga, memperkokoh tembok penyengker, dan menambah keindahan bagian depan pekarangan. Telajakan Desa Pakraman Nyuh Kuning mengalami perkembangan komponen seperti ukuran, bentuk atau model dan fungsinya. Dari segi ukuran, ada beberapa telajakan mengalami perubahan dari $100 \mathrm{~cm}$ menjadi sekurang-kurangnya $75 \mathrm{~cm}$.

3. Jenis tanaman yang ditanam pada telajakan saat ini didominasi oleh tanaman bunga seperti: kamboja $88 \%$, kembang sepatu $5 \%$, jempiring $3 \%$, kembang kertas $2 \%$ dan mawar $2 \%$. Jenis tanaman buah-buahan diantaranya: mangga $42 \%$, rambutan 29\% dan kelapa 29\%. Jenis rumput yaitu: rumput Gajah Mini 55\%, rumput Mutiara 28\% dan rumput Jepang 17\%.

4. Antusiasme warga Desa Pakraman Nyuh Kuning sangat tinggi seperti taatnya warga terhadap awig-awig mengenai telajakan yang telah disahkan pada tahun 1994, dan adanya tim lingkungan yang bekerja khusus dalam menjaga pelestarian telajakan Desa Pakraman Nyuh Kuning.

\subsection{Saran}

Beberapa hal yang disarankan dari penelitian ini antara lain:

1. Perlu dilakukan penelitian lebih lanjut mengenai konsep dan fungsi telajakan di berbagai daerah lainnya sebagai sumber acuan referensi dikemudian hari.

2. Perlunya peran masyarakat untuk tetap menjaga eksistensi telajakan di setiap rumah sebagai salah satu warisan leluhur taman tradisional Bali. 
3. Bagi masyarakat Desa Pakraman Nyuh Kuning supaya menanam tanaman hias lainnya yang memiliki warna agar telajakan lebih terlihat berwarna dan meriah. Penanaman kamboja agar sesuai dengan pengider bhuwana seperti: bagian utara kamboja dengan bunga yang gelap, timur kamboja dengan bunga putih, selatan dengan bunga merah dan pada bagian barat dengan bunga kuning. Pemberian lampu berwarna di setiap telajakan dengan berbagai warna akan menambah kesan yang istimewa dan meriah untuk di malam hari.

\section{Daftar Pustaka}

Amirin, T.M. Populasi dan Sampel Penelitian 3: Pengambilan sampel dari populasi TakTerhingga dan Tak-Jelas. Wordpress. 30 Juni 2009. Antariksa. 25 Juni 2014 $<$ tatangmanguny.wordpress.com>.

Desa Mas Kecamatan Ubud Kabupaten Gianyar. 1994. Awig-awig Desa Adat Nyuh Kuning.

Desa Pakraman Nyuh Kuning. 2012. Statistik Desa Pakraman Nyuh Kuning.

Dwijendra, N.K.A. 2010. Arsitektur Rumah Tradisional Bali. Denpasar: Udayana University Press.

Muka, I.K. Wawancara Pribadi. 5 Januari 2015. Desa Pakraman Nyuh Kuning, Gianyar.

Peta Desa Pakraman Nyuh Kuning, Ubud. Available online at: http//:forum.realityfanforum.com. (accessed 20 November 2013).

Sardiana, IK., N.M. Wiasti dan N. Wardi. 2012. Etnobotani Bali. Denpasar: Udayana University Press.

Sugiartha. Wawancara Pribadi. 15 Desember 2014. Desa Pakraman Nyuh Kuning Ubud, Gianyar.

Weda, Md. Wawancara Pribadi. 5 Desember 2015. Desa Pakraman Nyuh Kuning Ubud, Gianyar.

Windia, W. P. 2010, Dari Bali Mawacara Menuju Bali Santi. Denpasar: Udayana University Press. 